\title{
A Cross-Sectional Observation of the Effects of Hydrazine Hydrate on Workers' Health
}

\author{
Tetsuo Nomirama ${ }^{1}$, Kazuyuki OmaE ${ }^{1}$, Shigeru Tanaka ${ }^{2}$, Hiroyuki Mryauchi ${ }^{3}$, \\ Akio KoIzUmi ${ }^{4}$, Mikako Tsukada ${ }^{4}$, Yasuhiko WAdA ${ }^{4}$, Takashi Mogi ${ }^{4}$, \\ Shunichiro IMAMIYA ${ }^{3}$ and Haruhiko SAKURAI ${ }^{1}$ \\ 'Department of Preventive Medicine and Public Health, School of Medicine, Keio University, \\ ${ }^{2}$ Faculty of Hygienic Technology, School of Allied Health Sciences, Kitasato University, \\ ${ }^{3}$ The Association of Industrial Health and ${ }^{4}$ Department of Hygiene, School of Medicine, Akita University
}

\begin{abstract}
A Cross-Sectional Observation of the Effects of Hydrazine Hydrate on Workers' Health: Tetsuo Nomirama, et al. Department of Preventive Medicine and Public Health, School of Medicine, Keio University-Objective: To clarify the current and cumulative effects of hydrazine hydrate $(\mathrm{HH})\left(\mathrm{N}_{2} \mathrm{H}_{4}\right.$. $\mathrm{H}_{2} \mathrm{O}$ : CAS No. 7803-57-8) on workers' health. Methods: A cross-sectional survey was carried out on 172 male $\mathrm{HH}$-exposed workers (age 18-60, mean 39.6; exposure duration 0.50-34.17) and 125 male referent workers (age 19-58, mean 40.9) at 5 factories making $\mathrm{HH}$ or hydrazine derivatives in Japan. Current exposure concentrations were assessed by determining hydrazine in the breathing zones and urinary hydrazine + acetylhydrazine. The cumulative exposure level was assessed by multiplying the individuals' working durations at the job sites and the estimated past environmental levels at the job sites. Clinical examinations were performed with particular focus on hepatic and renal function tests. $\mathrm{N}$-acetyltransferase (NAT2) phenotypes were assessed. Acute and chronic subjective symptoms related to $\mathrm{HH}$ were examined by self-administered questionnaires. Results: No hydrazine was detected in either the breathing zones or the urine of the referent workers. The mean hydrazine concentration in the breathing zones, hydrazine + acetylhydrazine in urine, and cumulative exposure level were 0.0109 ppm (N.D. -0.2003$), 0.8660$ $\mu \mathrm{mol} / \mathrm{g} \cdot \mathrm{Cr}$ (N.D. -14.20$)$, and $2.80 \mathrm{ppm}$-years $(0.003-$ 19) respectively. There was no difference and no dosedependent change in either the means or the prevalence of abnormal findings in health examination items between the $\mathrm{HH}$-exposed and the referent workers
\end{abstract}

Received July 18, 1997; Accepted Jan 12, 1998

Correspondence to: T. Nomiyama, Department of Preventive Medicine and Public Health, School of Medicine, Keio University, 35 Shinanomachi, Shinjuku-ku, Tokyo 160-8582, Japan. e-mail: nomiyama@med.keio.ac.jp after adjusting confounding factors and by means of the differences of NAT2 phenotypes. Among 90 subjective symptoms, complaint of "nightmares" was significantly related to $\mathrm{HH}$ exposure. Conclusion: In this study, no health effect regarding current and cumulative $\mathrm{HH}$ exposure was observed in the $\mathrm{HH}$-exposed workers when compared to the referent workers. (J Occup Health 1998; 40: 177-185)

Key words: Hydrazine hydrate, NAT2, Polymorphism, Cross-sectional study, Phenotype

Hydrazine hydrate $\left(\mathrm{N}_{2} \mathrm{H}_{4} \cdot \mathrm{H}_{2} \mathrm{O}\right.$ : CAS No. 7803-57-8, abbreviated below as $\mathrm{HH}$ ) is a colorless, fuming, and oily liquid with an ammonia-like odor. $\mathrm{HH}$ is used as a reducing agent, an oxygen scavenger in treatment of boiler water, and as a source for drugs--hydralazine is an anti-tubercular drug-as well as for agricultural chemicals, and other hydrazine derivatives. The consumption of $\mathrm{HH}$ was about 12,300 $\mathrm{t}$ in Japan in 1995 and about 48,500 $\mathrm{t}$ in the world in 1992. Hydrazine $\left(\mathrm{N}_{2} \mathrm{H}_{4}\right.$, CAS No. 302-01-2) is used as a high-energy rocket fuel, though its in this application is limited.

The $\mathrm{LD}_{50}$ by oral administrations were $83 \mathrm{mg} / \mathrm{kg}$ in white mice and $129 \mathrm{mg} / \mathrm{kg}$ in albino rats ${ }^{1}$. $\mathrm{LD}_{50}$ by dermal administrations were $164 \mathrm{mg} / \mathrm{kg}$ and $140 \mathrm{mg} / \mathrm{kg}$ in male and female rabbits ${ }^{2)}$. The $\mathrm{LC}_{50}$ after administrations through inhalation for one hour were $9.0 \mathrm{mg} / \mathrm{l}$ in male Sprague-Dawley (SD) rats and $5.3 \mathrm{mg} / l$ in female SD rats $^{33}$. In case reports, although there was no information about environmental concentrations, acute exposure to $\mathrm{HH}$ caused hepatic, renal, and neurological dysfunction ${ }^{4)}$. Subchronic or chronic exposure and drinking by mistake induced hepatic, renal, and neurological dysfunction and contact dermatitis-like effect ${ }^{5-7}$. . HH exposure for an average of 20 years did not lead an excessive rate of cancer deaths or diseased commonly associated with 
$\mathrm{HH}^{8,9)}$. We did not find any carcinogenesis studies of $\mathrm{HH}$, but hydrazine inhalation was found to induce nasal and lung tumors in mice ${ }^{10,11)}$ and in rats ${ }^{12}$. Based on the positive results of animal studies, hydrazine was classified as Group 2B (possibly carcinogenic to humans) by the International Agency for Research on Cancer (IARC) ${ }^{13 .}$ and as $3 \mathrm{~A}$ (animal carcinogen) by the American Conference of Governmental and Industrial Hygienists (ACGIH) ${ }^{14}$.

The aim of this cross-sectional study is to clarify the relationship between current and cumulative $\mathrm{HH}$ exposure and its health effects by means of the differences of $\mathrm{N}$ acetyltransferase (NAT2) phenotypes.

\section{Subjects and Methods}

\section{Study population}

The study population included 172 male $\mathrm{HH}$ or hydrazine derivative manufacturing workers $(\mathrm{HH}-$ exposed workers) and 125 referent workers in 5 factories in Japan. Almost none of the $\mathrm{HH}$-exposed workers wore any respiratory protective devices during the regular operations. Most workers worked three shifts. Referent workers were recruited from the same factories and matched by age ( \pm 2 years).

After informing the subjects of the study's outline and items of examination, we obtained their informed consent for collecting blood and urine samples and for gathering the information regarding subjective symptoms required on the questionnaires.

\section{Exposure assessment}

$\mathrm{HH}$ exposure levels were assessed by determining the amount of hydrazine in the breathing zones and the urinary excretion of hydrazine and acetylhydrazine, the major metabolites of NAT2. HH-exposed workers wore sampling tubes filled with activated charcoal on their collars and sampling pump units on their waists for 8-hr work shifts. Adsorbed hydrazine was determined by a modified method of NIOSH ${ }^{(5)}$. In 3 factories where seasonal fluctuations in hydrazine concentrations were expected to be high, $\mathrm{HH}$ in the breathing zone was determined twice in hot and cold seasons and the average of 2 measurements was used for analysis.

Urine samples were collected at the end of the individuals' work shifts on the same day as the $\mathrm{HH}$ sampling in the breathing zone. Urine samples were immediately frozen and stored at $-20^{\circ} \mathrm{C}$ until analyzed. Hydrazine and acetylhydrazine levels in urine were determined by the method of Timbrell et al. ${ }^{16)}$. In order to confirm that none of the referent workers had been exposed to $\mathrm{HH}$, air samples from the breathing zone and urine were collected from 27 and 106 of the referent workers, respectively, in the same way as those taken from the $\mathrm{HH}$-exposed workers and the $\mathrm{HH}$-exposure levels were determined.

Although past exposure levels of $\mathrm{HH}$ were not systematically measured in all factories, hydrazine concentrations sporadically determined in work sites were available. Thus, the cumulative $\mathrm{HH}$ exposure level in each $\mathrm{HH}$-exposed worker was estimated as the product of the hydrazine concentration at the work site multiplied by the length of time the individual had worked at the site. Because the operating length of one plant was short and its workers' exposure levels were expected to be very low, the cumulative exposure level of each worker was not estimated in this factory.

\section{Phenotype of NAT2}

Phenotype of NAT2 activity in each worker was assessed by detecting mutations of the NAT2 gene in peripheral leucocytes according to the method of Lin et al. ${ }^{17}$.

\section{Health effect assessment}

Subjective symptom assessment: The subjects were asked to complete four types of self-administered questionnaires for subjective symptoms which included the following items: 1) 54 subjective symptoms ${ }^{18 \text { ) }}$ and 6 additional symptoms related to $\mathrm{HH}$ exposure over the previous 6 months; 2) 11 subjective symptoms complained of before starting daily work, 7 questions about smoking, alcohol consumption, caffeine intake, and symptoms which are induced after caffeine intake (e.g., insomnia, headache) and are indirect indicators of the NAT2 phenotype; 3) 19 subjective symptoms during or after finishing daily work; 4) 19 questions about past and present medical history, medical drug use, health effects induced by exposure to any kind of chemical products or other medications.

Clinical examinations: Blood samples were collected from the antecubital vein. Urinary samples for clinical examinations were also collected at the same time as blood sampling and the hematological and biochemical examinations were performed within a day. Hematological or biochemical items (Table 4) were determined by an automated hemocytometer (SE9000, Sysmex) and an automatic clinical analyzer (736-60, Hitachi, Ltd.). Protein, glucose, bilirubin, ketone body in urine, hepatitis $B$ antigen (HBs-Ag), antibody (HBs-Ab), and hepatitis C antibody $(\mathrm{HCV}-\mathrm{Ab})$ in serum were determined.

Prevalence rates of diseases in recent 3 years: In 3 factories, information regarding worker's health insurance claims for the purpose of billing health care cost during 1992 through 1994 was available. We took the data provided in the additional referent workers' medical insurance claims in their factories to obtain a statistical power. We noted diseases possibly related to $\mathrm{HH}$ exposure and calculated three-year prevalence rates of the diseases. Risks of the diseases in $\mathrm{HH}$-exposed workers were assessed with rate ratios.

\section{Statistical analysis}

One-way ANOVA was applied to compare means of 
variables with the interval scales between or among groups. For prevalence data, $2 \times 2$ or $\mathrm{m} \times \mathrm{n}$ table analysis was applied. To adjust the effects of confounding variables, the multiple regression procedure, multiple logistic regression procedure, stratification method, and the matching method were used as needed.

\section{Results}

\section{Study population}

Forty-eight workers were excluded from the statistical analysis of the hematological, biochemical, and urinary examinations, because 43 were hepatitis $\mathrm{B} / \mathrm{C}$ antigen or antibody positive (HH-exposed workers HBs-Ag (+) 1 , $\mathrm{HBs}-\mathrm{Ab}(+) 13, \mathrm{HCV}-\mathrm{Ab}(+) 0$, Referent workers HBs$\mathrm{Ag} \mathrm{(+)} \mathrm{6,} \mathrm{HBs-Ab} \mathrm{(+)} \mathrm{20,} \mathrm{HCV-Ab} \mathrm{(+)} \mathrm{3)} \mathrm{and} 5$ were under the medication of diabetes mellitus. Total number of members analyzed were $140 \mathrm{HH}$-exposed workers and 109 referent workers. Table 1 shows the characteristics of the study population analyzed. The mean ages of $\mathrm{HH}$ exposed workers and referent workers were 39.6 (range: 18-60) and 40.9 years (range: $19-58$ ) respectively. The mean duration of exposure on $\mathrm{HH}$-exposed workers was 13.37 years (range: $0.50-34.17$ ). There was no significant difference between the two groups regarding mean age, educational status, or the amount of alcohol consumption except the higher proportion of heavy smokers among HH-exposed workers.

\section{Exposure assessment}

Neither hydrazine nor acetylhydrazine was detected in the samples from the referent workers. Table 2 gives the results for the hydrazine exposure concentration in the breathing zones and the biological exposure indices of the $\mathrm{HH}$-exposed workers. The levels of all samples below detection limits were assigned as half values of the detection limits. The arithmetical mean of the hydrazine concentration was $0.0109 \mathrm{ppm}$ which was over $0.01 \mathrm{ppm}$ of the occupational exposure limits recommended by $\mathrm{ACGIH}^{14)}$ and the Japan Society of Occupational Health (tentative value proposed in 1994) ${ }^{19}$. The number of workers who were exposed to $0.01 \mathrm{ppm}$ or above was 28 $(21.5 \%)$, and the number exposed to $0.10 \mathrm{ppm}$ or above was $2(1.5 \%)$ of the $130 \mathrm{HH}$-exposed workers.

\section{Cumulative exposure assessment}

The distribution of the cumulative exposure (ppm-

Table 1. Characteristics of the study population

\begin{tabular}{lccccccccc}
\hline & \multicolumn{4}{c}{ HH-exposed workers } & \multicolumn{5}{c}{ Referent workers } \\
\hline & & $\mathrm{n}$ & Mean & SD & n & Mean & SD \\
Age (years) & & 140 & 39.6 & 12.8 & & 109 & 40.9 & 11.1 \\
Exposure duration (years) & 140 & 13.37 & 10.63 & & - & - & - & \\
Educational status & & 1 & 2 & 3 & 4 & 1 & 2 & 3 & 4 \\
& $\mathrm{n}$ & 22 & 108 & 6 & 4 & 16 & 81 & 6 & 6 \\
Drinking (g/day) & & 0 & $0-25$ & $25-50$ & $50-$ & 0 & $0-25$ & $25-50$ & $50-$ \\
& $\mathrm{n}$ & 63 & 33 & 26 & 18 & 36 & 33 & 21 & 21 \\
Smoking (/day) & & 0 & $0-15$ & $15-30$ & $30-$ & 0 & $0-15$ & $15-30$ & $30-$ \\
& $\mathrm{n}$ & 50 & 15 & 56 & $19 *$ & 42 & 17 & 46 & 4 \\
\hline
\end{tabular}

HH: hydrazine hydrate. Educational status: graduated from 1: junior high school, 2: high school, 3: junior college, 4: college. $*$ : $\mathrm{p}<0.05$.

Table 2. Environmental hydrazine concentrations in environment and hydrazine and acetylhydrazine concentrations in the urine of hydrazine hydrate-exposed workers

\begin{tabular}{lcccccc}
\hline & $\mathbf{n}$ & Mean & SD & GM & GSD & Range \\
\hline Exposure concentration (ppm) & 130 & 0.0109 & 0.0333 & 0.0013 & 8.4086 & N.D.- 0.2003 \\
U hydrazine & 139 & 0.8072 & 1.9825 & 0.2039 & 4.0587 & N.D.-13.0625 \\
U acetylhydrazine & 139 & 0.0588 & 0.1730 & 0.0113 & 3.7905 & N.D.- 1.1419 \\
U hydrazine + acetylhydrazine & 139 & 0.8660 & 2.1555 & 0.2153 & 3.9941 & N.D.-14.2044 \\
\hline
\end{tabular}

$\mathrm{U}$ hydrazine, $\mathrm{U}$ acetylhydrazine, and $\mathrm{U}$ hydrazine + acetylhydrazine: urinary hydrazine ( $\mu \mathrm{mol} / l)$, urinary acetylhydrazine $(\mu \mathrm{mol} / l)$, and urinary hydrazine + acetylhydrazine $(\mu \mathrm{mol} / l)$. N.D.: not detectable. Exposure concentration $<0.0004 \mathrm{ppm}, \mathrm{U}$ hydrazine $<0.156 \mu \mathrm{mol} / l$, U acetylhydrazine $<0.135 \mu \mathrm{mol} / l$. GM: geometric mean. GSD: geometric standard deviation. 
years) is illustrated in Fig. 1. The cumulative hydrazine exposure levels' arithmetical mean was 2.80 ppm-years and the geometric mean was 0.42 ppm-years (range: 0.003-19 ppm-years). Fig. 2 (a)-(d) shows hydrazine

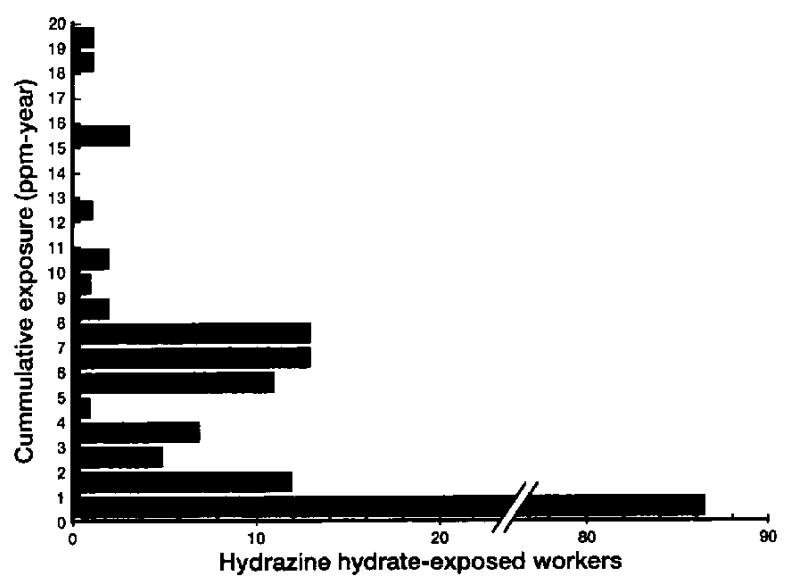

Fig. 1. Cumulative hydrazine hydrate exposure (ppm-year). concentrations by year estimated from sporadic hydrazine determinations and histories of technological changes or improvements in each work site. Before the 1970's, company records of the concentrations and the workers' experiences in detecting HH's odor whose scent threshold is more than 1 ppm showed the exposure levels at 2 of 4 factories' work sites to be up to or above $1 \mathrm{ppm}$.

\section{NAT2 phenotype frequency}

Table 3 shows the results for NAT2 type frequency. There was no difference in the NAT2 phenotype frequency among 5 factories and 3 districts, Shikoku, Tokai, and Hokuriku, in Japan (data not shown) and between the $\mathrm{HH}$-exposed and the referent workers.

\section{Health effects assessment}

Clinical laboratory examinations: Tables 4 and 5 show the mean and standard deviations of clinical laboratory examinations of $\mathrm{HH}$-exposed and referent workers, and the prevalence of workers with values outside the normal ranges. The levels of FFA were significantly higher in the $\mathrm{HH}$-exposed workers than that in the referent workers,

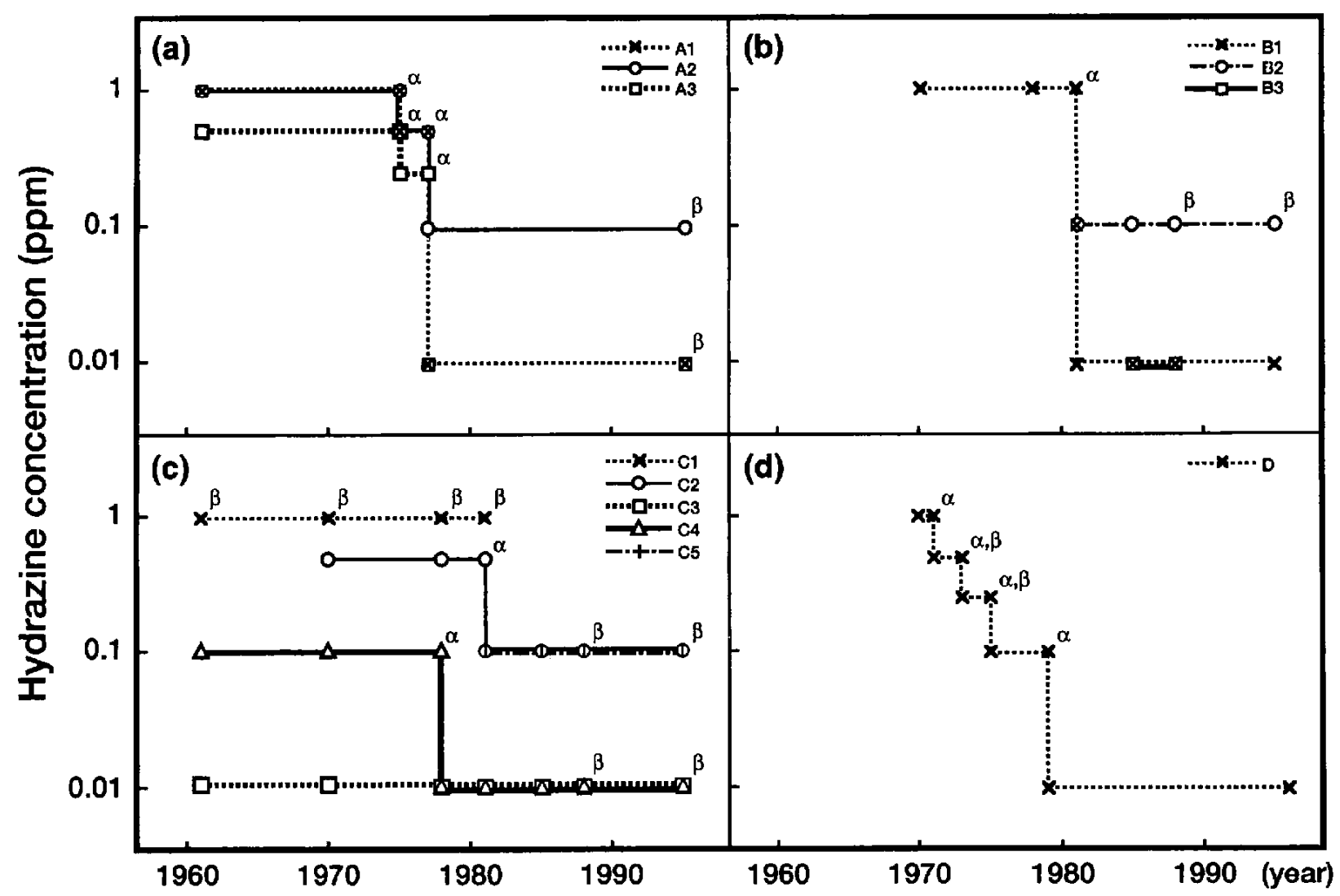

Fig. 2. The estimated hydrazine concentrations in 4 factories ((a)-(d)). $\alpha$ indicates that at this point there were some technological changes or improvements in each work site. $\beta$ indicates the point where hydrazine concentrations in the factories were determined by the various kinds of methods, i.e., measured with a stain tube or sampled with activated charcoal and measured by the colorimetric method or the NIOSH method (1977) ${ }^{(5)}$. 
while it did not show the difference in the prevalence of workers with values outside the normal ranges and the dose-dependent increase. The levels of potassium were also significantly higher in the $\mathrm{HH}$-exposed workers than those in the referent workers, and the prevalence in the $\mathrm{HH}$-exposed workers with the values of potassium outside the normal range was also higher than that in the referent group. In one factory, a technical problem resulted in the blood samples of a larger number of $\mathrm{HH}$-exposed workers than referent workers showing signs of hemolysis. After excluding the data for this factory, potassium did not show any significant increase in the $\mathrm{HH}$-exposed workers. There were significant differences in the means of AST, ALT, DBil, RBC, and platelet among lower HH-exposed, higher $\mathrm{HH}$-exposed, and referent workers. Ali of these items showed no exposure-dependent changes and some of them were better values in the $\mathrm{HH}$-exposed workers. Table 6 shows the results of clinical laboratory examinations for cumulative HH exposure levels and NAT2 phenotypes. Workers with cumulative $\mathrm{HH}$ exposure levels of $5 \mathrm{ppm}$-year or above (workers with higher cumulative exposure levels) were 9 years older than the referent workers and 13 years older than those with cumulative exposure levels below 5 ppm-year (workers with lower cumulative exposure levels). The levels of TTT, ZTT, DBil, Alb, $\mathrm{HBA}_{\mathrm{tc}}$, potassium, and $\boldsymbol{\beta}_{2}$-MG were significantly different in means among workers with higher cumulative exposure, workers with lower cumulative exposure, and referent workers. However, differences in mean levels of only ZTT remained significant after using multiple regression analysis to adjust for the effects of age, education, alcohol intake, and smoking.

Differences in NAT2 phenotypes among the subjects did not affect the results of clinical laboratory examinations.

Subjective symptoms: No significant increase in the prevalence of $90 \mathrm{HH}$ exposure-related symptoms was observed between the HH-exposed workers and the referent workers. However, complaints of "nightmares" were significantly related to $\mathrm{HH}$ exposure, and its odds ratio was 3.76 (95\% Confidence Interval: 1.39-10.10) after adjusting for age, educational status, alcohol intake, and smoking using multiple logistic regression procedure. No significant increase in the prevalence of such complaints among workers with higher cumulative exposure levels were observed. Differences among NAT2 phenotypes had no effect on the prevalence of the subjective symptoms.

Prevalence of diseases during 1992-1994: The rate ratios of three-year prevalence of viral hepatitis (rate ratio $1.99,95 \% \mathrm{CI} 1.15-3.43$ ), liver cirrhosis (rate ratio 2.48 , $95 \%$ CI 1.51-4.08), thyroid disorder (rate ratio 2.48, 95\% CI 1.51-4.08), and cerebrovascular disease other than cerebral infarction (rate ratio $2.26,95 \% \mathrm{CI} 1.35-3.78$ ) were significantly greater.

\section{Discussion}

In this cross-sectional study, 48 out of 297 workers were excluded from the hematological and biochemical examinations' statistical analyses because of past hepatitis viral infections and because they were under medication for diabetes mellitus. The prevalences of HBs-Ag, HBs$\mathrm{Ab}$, and $\mathrm{HCV}-\mathrm{Ab}$ positive in $\mathrm{HH}$-exposed and referent workers were not significantly different, and these prevalences in both $\mathrm{HH}$-exposed and referent workers were in the range of the normal background levels in Japan ${ }^{20-22)}$. Because we could not obtain unbiased information about retired or resigned workers with past $\mathrm{HH}$ exposure, we could not avoid survival selection bias in the current $\mathrm{HH}$-exposed workers surveyed.

In the hematological and biochemical examinations, the significantly higher levels of FFA in the HH-exposed workers seemed not to be due to the $\mathrm{HH}$ exposure because there was no difference in the prevalence of workers with values of FFA outside the normal range and no dosedependent increase and the sampling time was at any time. As the significance of the levels of potassium in the HHexposed workers disappeared after the exclusion of the data from the factory workers whose blood samples proved hemolytic, it can be suggested that high potassium levels were not due to the $\mathrm{HH}$ exposure but due to the hemolysis of blood samples. The significant differences

Table 3. Results of NAT2 type of allele or phenotype frequency among all examined hydrazinehydrate-exposed and referent workers

\begin{tabular}{cccccccc}
\hline & \multicolumn{3}{c}{ Allele } & \multicolumn{3}{c}{ Phenotype } \\
& 1 & 2 & 3 & 4 & Rapid & Int $^{\text {a }}$ & Slow \\
\hline HH-exposed workers & 226 & 34 & 75 & 9 & 74 & 78 & 20 \\
\% & 65.7 & 9.9 & 21.8 & 2.6 & 43.0 & 45.3 & 11.6 \\
Referent workers & 174 & 21 & 53 & 2 & 59 & 58 & 8 \\
$\%$ & 69.6 & 8.4 & 21.2 & 0.8 & 47.2 & 46.4 & 6.4 \\
Total & 400 & 55 & 128 & 11 & 133 & 136 & 28 \\
$\%$ & 67.3 & 9.3 & 21.5 & 1.9 & 44.8 & 45.1 & 10.1 \\
\hline
\end{tabular}

HH: hydrazine hydrate. a: Intermediate. 
Table 4. Mean results of hematological and biochemical examinations by present exposure categories

\begin{tabular}{|c|c|c|c|c|c|c|c|c|}
\hline & \multicolumn{2}{|c|}{ Refa } & \multicolumn{2}{|c|}{$\mathrm{HH}^{\mathrm{b}}$} & \multicolumn{2}{|c|}{$\operatorname{Low}^{\mathfrak{c}}$} & \multicolumn{2}{|c|}{ Highd } \\
\hline & Mean & $\mathrm{SD}$ & Mean & SD & Mean & SD & Mean & $\mathrm{SD}$ \\
\hline $\mathrm{n}$ & 109 & & 140 & & 110 & & 30 & \\
\hline Age & 40.9 & 11.1 & 39.6 & 12.8 & 39.6 & 12.6 & 39.3 & 13.7 \\
\hline$W_{B C} e\left(/ \mathrm{mm}^{3}\right)$ & 6510.7 & 1.3 & 6736.0 & 1.3 & 6984.2 & 1.3 & 5883.4 & 1.3 \\
\hline $\mathrm{RBC}^{\mathrm{e}}\left(\times 10^{4 / \mathrm{mm}^{3}}\right)$ & 486.7 & 35.3 & 488.0 & 35.6 & 487.1 & 36.3 & 491.3 & $33.4^{* *}$ \\
\hline $\mathrm{Hb}^{\mathrm{e}}(\mathrm{g} / \mathrm{d} l)$ & 15.42 & 1.02 & 15.41 & 1.07 & 15.44 & 1.12 & 15.33 & 0.93 \\
\hline $\mathrm{Ht}=(\%)$ & 45.90 & 3.04 & 45.74 & 3.22 & 45.91 & 3.38 & 45.15 & 2.56 \\
\hline Platelet $\mathrm{e}\left(\times 10^{4} / \mathrm{mm}^{3}\right)$ & 22.97 & 1.27 & 22.58 & 1.20 & 23.12 & 1.18 & 20.68 & $1.28 *$ \\
\hline $\operatorname{AST}(\mathrm{G})(\mathrm{IU} / l)$ & 22.4 & 1.5 & 20.4 & $1.4^{*}$ & 20.9 & 1.5 & 18.5 & $1.3^{*}$ \\
\hline $\operatorname{ALT}(\mathrm{G})(\mathrm{IU} / l)$ & 26.4 & 1.8 & 22.8 & 1.8 & 24.0 & 1.8 & 19.0 & $1.9^{*}$ \\
\hline$\gamma \mathrm{GTP}(\mathrm{G})(\mathrm{IU} / l)$ & 26.9 & 2.1 & 22.7 & 1.9 & 23.7 & 1.8 & 19.4 & 2.1 \\
\hline $\mathrm{LDH}(\mathrm{G})(\mathrm{IU} / l)$ & 323.3 & 1.2 & 313.5 & 1.2 & 314.3 & 1.2 & 310.3 & 1.2 \\
\hline $\operatorname{ALP}(\mathrm{G})(\mathrm{IU} / l)$ & 161.5 & 1.3 & 166.3 & 1.3 & 167.1 & 1.3 & 163.5 & 1.3 \\
\hline TTT (G) (U) & 0.94 & 2.25 & 1.02 & 2.27 & 1.04 & 2.18 & 0.97 & 2.66 \\
\hline $\operatorname{ZTT}(\mathbf{G})(\mathrm{U})$ & 6.17 & 1.62 & 6.89 & 1.49 & 6.88 & 1.49 & 6.94 & 1.54 \\
\hline $\mathrm{T}-\mathrm{Bil}(\mathrm{G})(\mathrm{mg} / \mathrm{d} l)$ & 0.64 & 1.52 & 0.58 & 1.47 & 0.60 & 1.47 & 0.55 & 1.21 \\
\hline D-Bil $(\mathrm{mg} / \mathrm{d} l)$ & 0.31 & 0.16 & 0.26 & 0.13 & 0.27 & 0.14 & 0.26 & $0.15^{*}$ \\
\hline I-Bil $(\mathrm{mg} / \mathrm{d} l)$ & 0.39 & 0.18 & 0.36 & 0.16 & 0.37 & 0.16 & 0.34 & 0.18 \\
\hline Ch-E (IU $/ l)$ & 5025.3 & 827.5 & 5029.4 & 845.3 & 5043.1 & 837.7 & 4979.1 & 885.6 \\
\hline $\mathrm{TP}(\mathrm{mg} / \mathrm{d} l)$ & 7.32 & 0.44 & 7.31 & 0.34 & 7.33 & 0.36 & 7.25 & 0.28 \\
\hline Alb $(\mathrm{mg} / \mathrm{d} l)$ & 4.58 & 0.30 & 4.56 & 0.25 & 4.57 & 0.28 & 4.57 & 0.17 \\
\hline $\mathrm{A} / \mathrm{G}$ & 1.68 & 0.20 & 1.68 & 0.21 & 1.67 & 0.22 & 1.72 & 0.16 \\
\hline $\mathrm{T}$-Chol $(\mathrm{mg} / \mathrm{d} l)$ & 196.1 & 38.0 & 188.9 & 31.9 & 190.9 & 30.4 & 181.6 & 36.8 \\
\hline $\mathrm{TG}(\mathrm{G})(\mathrm{mg} / \mathrm{d} l)$ & 139.4 & 1.9 & 130.9 & 1.8 & 135.4 & 1.8 & 115.5 & 1.9 \\
\hline $\mathrm{FFA}(\mathrm{G})(\mathrm{mEq} / \mathrm{d} l)$ & 0.27 & 1.81 & 0.32 & $1.83 *$ & 0.34 & 1.80 & 0.29 & $1.95^{*}$ \\
\hline $\mathrm{HDL}(\mathrm{mg} / \mathrm{d} l)$ & 50.8 & 11.6 & 49.5 & 12.8 & 48.9 & 12.9 & 51.6 & 12.6 \\
\hline $\mathrm{LDL}(\mathrm{mg} / \mathrm{d} l)$ & 466.3 & 105.1 & 450.5 & 105.4 & 456.0 & 107.3 & 430.3 & 97.1 \\
\hline $\operatorname{VLDL}(\mathrm{G})(\mathrm{mg} / \mathrm{d} l)$ & 108.0 & 1.7 & 100.4 & 1.7 & 103.3 & 1.7 & 90.5 & 1.6 \\
\hline Chylomicron $(\mathrm{G})(\mathrm{mg} / \mathrm{d} l)$ & 59.6 & 2.2 & 61.6 & 2.2 & 64.4 & 2.1 & 52.3 & 2.4 \\
\hline Fructosamine $(\mathrm{G})(\mathrm{mg} / \mathrm{d} l)$ & 247.0 & 1.1 & 245.2 & 1.1 & 245.1 & 1.1 & 245.7 & 1.1 \\
\hline $\mathrm{HbA}_{\mathrm{Ic}}(\mathrm{G})(\%)$ & 4.91 & 1.08 & 4.91 & 1.08 & 4.91 & 1.09 & 4.93 & 1.10 \\
\hline $\mathrm{Cr}(\mathrm{mg} / \mathrm{d} l)$ & 0.94 & 0.13 & 0.92 & 0.11 & 0.92 & 0.11 & 0.94 & 0.10 \\
\hline $\mathrm{UA}(\mathrm{mg} / \mathrm{d} l)$ & 5.49 & 1.34 & 5.56 & 1.10 & 5.55 & 1.08 & 5.61 & 1.22 \\
\hline $\mathrm{BUN}(\mathrm{mg} / \mathrm{d} l)$ & 13.3 & 3.3 & 13.7 & 3.5 & 13.6 & 3.4 & 14.4 & 3.7 \\
\hline $\mathrm{Na}(\mathrm{mEq} / \mathrm{l})$ & 140.5 & 2.0 & 140.7 & 2.1 & 140.7 & 2.1 & 140.8 & 2.1 \\
\hline $\mathbf{K}(\mathrm{G})(\mathrm{mEq} / \mathrm{l})$ & 4.32 & 1.15 & 4.51 & $1.13 *$ & 4.44 & 1.12 & 4.73 & 1.15 \\
\hline $\mathrm{Cl}(\mathrm{mEq} / l)$ & 101.0 & 2.2 & 101.2 & 2.7 & 101.5 & 2.7 & 100.1 & 2.4 \\
\hline $\mathrm{Ca}(\mathrm{mg} / \mathrm{d} l)$ & 9.16 & 0.37 & 9.18 & 0.35 & 9.20 & 0.37 & 9.15 & 0.33 \\
\hline \multicolumn{9}{|l|}{ Urine } \\
\hline $\operatorname{NAG}(\mathrm{G})(\mathrm{U} / l)$ & 3.32 & 2.50 & 3.62 & 2.23 & 3.60 & 2.30 & 3.71 & 2.02 \\
\hline$\beta_{2}-\mathrm{MG}(\mathrm{G})(\mu \mathrm{g} / \mathrm{g} \cdot \mathrm{Cr})$ & 153.7 & 1.8 & 156.4 & 1.7 & 153.3 & 1.8 & 161.2 & 1.8 \\
\hline
\end{tabular}

WBC: total leucocyte. RBC: erythrocyte. Hb: hemoglobin. Ht: hematocrit. AST: asparate aminotransferase. ALT: alanine aminotransferase. $\gamma$ GTP: $\gamma$ glutamyl transpeptidase. LDH: lactate dehydrogenase. ALP: alkaline phosphatase. TTT: thymol tubbidity test. ZTT: zinc sulfate tubbidity test. T-Bil: total bilirubin. D-Bil: direct bilirubin. I-Bil: indirect bilirubin. Ch-E: cholinesterase. TP: total protein. Alb: albumin. A/G: albumin/globlin ratio. T-Chol: total cholesterol. TG: triglyceride. FFA: free fatty acid. HDL: high density lipoprotein. LDL: low density lipoprotein. VLDL: very low density lipoprotein. $\mathrm{HbA}_{1 \mathrm{c}}$ : hemoglobin $\mathrm{A}_{1 \mathrm{c}}$. Cr: creatinine. UA: uric acid. BUN: blood urea nitrogen. Na: sodium. K: potassium. Cl: chlorine. Ca: calcium. NAG: N-acetyl- $\beta$-D-glucosaminidase. $\beta_{2}$-MG: $\beta_{2}-$ microglobulin. (G): geometric mean and geometric standard deviation. a: Referent workers. b: Hydrazine hydrateexposed workers. c: Hydrazine hydrate-exposed workers exposed to less than $0.01 \mathrm{ppm}$. d: Hydrazine hydrate-exposed workers exposed to $0.01 \mathrm{ppm}$ or above. e: The numbers of Ref, HH, Low, and High were 105, 128, 101 and 27 respectively. ${ }^{*}, * * \mathrm{p}<0.05,0.01$ compared to referent workers. 
Table 5. Prevalence of workers with values outside the normal range

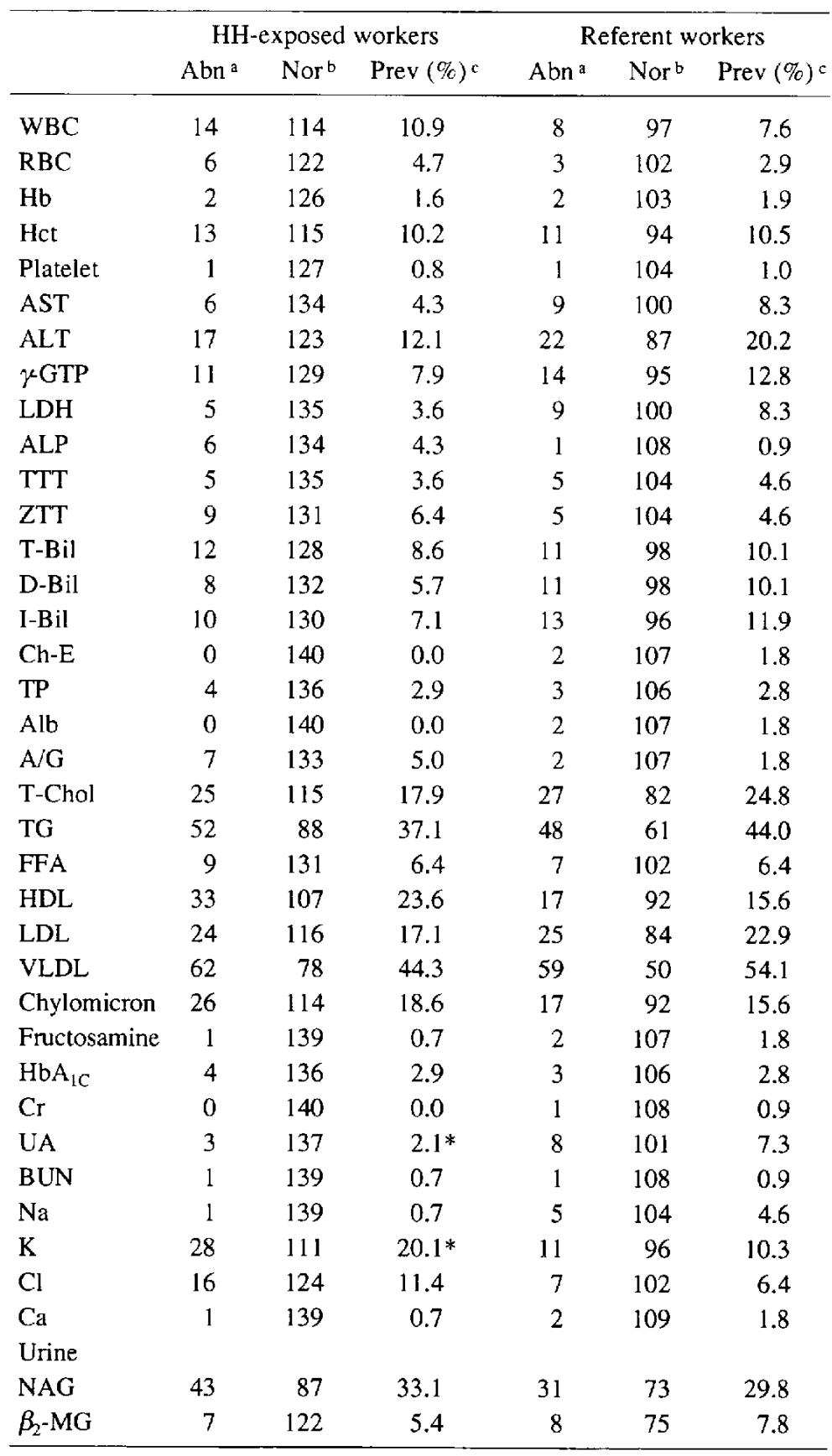

Abbreviations and units of the items are shown in Table 4. HH: hydrazine hydrate. a: Workers with values outside the normal ranges. b: Workers with values within the normal ranges. c: Prevalence of workers with values outside the normal ranges. $*$ : $\mathrm{p}<0.05$ compared to referent workers.

in mean levels of AST, ALT, D-Bil, RBC, and platelet between the $\mathrm{HH}$-exposed and the referent workers were not related to the $\mathrm{HH}$ exposure because the differences were not dose-dependent. As the significant differences in the levels of ZTT, D-Bil, Alb, $\mathrm{HbA}_{1 \mathrm{c}}$, and $\boldsymbol{\beta}_{2}$-MG among higher cumulative exposed, lower cumulative exposed, and referent workers disappeared after adjusting for age, educational status, alcohol intake, and smoking, they were found to be unrelated to the $\mathrm{HH}$ exposure but due to the older age in the higher cumulative exposed workers. Significant increase in TTT in the HH-exposed workers disappeared after the adjustment, but this may be by chance since no other liver dysfunction index related to $\mathrm{HH}$ exposure. The results of clinical laboratory examinations were not related to the difference among NAT2 phenotypes.

Because diagnostic criteria of the diseases mentioned on medical insurance claims are not unified, the prevalence of the diseases in this study includes some uncertainty and its quality is limited. In Japan, however, there is no disease registration system and the medical insurance claims are the only tool for estimating disease prevalence. It seems unlikely that the uncertainty is biased only in the $\mathrm{HH}$-exposed or referent workers, since doctors diagnosing the disease did not know whether their patients were exposed to HH or not, and had no interest in health effects of $\mathrm{HH}$. We therefore thought that analysis of the prevalence by using the medical insurance claims was useful in estimating the trend of disease. The higher rate ratio of hepatitis $\mathrm{B} / \mathrm{C}$ and liver cirrhosis may be caused by viral infection. Interpretation of higher rate ratios of thyroid disorders and cerebrovascular diseases in the $\mathrm{HH}$-exposed workers is now very difficult because no evidence was found in case studies, a mortality study, and animal experiments that $\mathrm{HH}$ exposure increased the risk of effects on the thyroid and cerebrovascular system. Further epidemiological study is necessary in this study population focused on thyroid function and the cerebrovascular system, and personal data collection from each worker diagnosed as thyroid disorder or cerebrovascular disease is also necessary if the problem of privacy protection is to be solved.

Only one complaint, "nightmares" in the preceding 6 months, in a total of 90 possible symptoms was significantly related to the $\mathrm{HH}$ exposure. Chronic exposure to some solvents and methyl bromide was reported to increase complaints of symptoms related to sleep quantity or quality and the complaint of 
Table 6. Mean results of hematological and biochemical examinations by cumulative exposure categories and NAT2 phenotypes

\begin{tabular}{|c|c|c|c|c|c|c|c|c|c|c|c|c|}
\hline & \multicolumn{6}{|c|}{ Cumulative exposure category } & \multicolumn{6}{|c|}{ NAT2 phenotype in HH-exposed workers } \\
\hline & \multicolumn{2}{|c|}{$\operatorname{Ref}^{a}$} & \multicolumn{2}{|c|}{ Low b } & \multicolumn{2}{|c|}{ High $\mathrm{c}$} & \multicolumn{2}{|c|}{ Rapid } & \multicolumn{2}{|c|}{ Intermediate } & \multicolumn{2}{|c|}{ Slow } \\
\hline & Mean & $\mathrm{SD}$ & Mean & $\mathrm{SD}$ & Mean & $\mathrm{SD}$ & Mean & SD & Mean & $\mathrm{SD}$ & Mean & SD \\
\hline $\mathrm{n}$ & 109 & & 82 & & 33 & & 55 & & 58 & & 15 & \\
\hline Age & 40.9 & 11.1 & $36.9^{* *}$ & 12.0 & 49.9 & 6.0 & 40.8 & 12.2 & 38.5 & 13.2 & 39.4 & 13.5 \\
\hline WBC & 6510.7 & 1.3 & 6826.8 & 1.0 & 6548.4 & 1.3 & 6565.9 & 1.3 & 6968.8 & 1.3 & 6487.7 & 1.3 \\
\hline RBC & 486.7 & 35.3 & 490.3 & 35.6 & 487.9 & 38.5 & 488.4 & 35.2 & 488.3 & 37.4 & 485.5 & 31.7 \\
\hline $\mathrm{Hb}$ & 15.42 & 1.02 & 15.41 & 1.12 & 15.55 & 1.00 & 15.45 & 1.19 & 15.42 & 1.02 & 15.29 & 0.89 \\
\hline Ht & 45.90 & 3.04 & 45.87 & 3.35 & 45.26 & 3.07 & 45.69 & 3.32 & 45.88 & 3.32 & 45.47 & 2.67 \\
\hline Platelet & 22.97 & 1.27 & 23.01 & 1.18 & 21.12 & 1.27 & 22.92 & 1.16 & 22.70 & 1.25 & 20.96 & 1.18 \\
\hline $\operatorname{AST}(G)$ & 22.4 & 1.5 & 19.9 & 1.0 & 21.0 & 1.1 & 20.6 & 1.4 & 20.1 & 1.5 & 20.3 & 1.3 \\
\hline $\operatorname{ALT}(G)$ & 26.4 & 1.8 & 22.3 & 1.8 & 23.0 & 1.7 & 22.8 & 1.9 & 22.5 & 1.8 & 24.1 & 1.6 \\
\hline$\gamma$ GTP $(\mathrm{G})$ & 26.9 & 2.1 & 22.9 & 1.9 & 25.7 & 1.9 & 24.8 & 2.1 & 21.2 & 1.7 & 21.7 & 1.9 \\
\hline $\mathrm{LDH}(\mathrm{G})$ & 323.3 & 1.2 & 311.6 & 1.2 & 316.1 & 1.1 & 307.4 & 1.2 & 315.5 & 1.2 & 329.5 & 1.1 \\
\hline $\operatorname{ALP}(G)$ & 161.5 & 1.3 & 169.5 & 1.3 & 163.0 & 1.3 & 165.9 & 1.3 & 168.1 & 1.3 & 160.4 & 1.2 \\
\hline TTT (G) & 0.94 & 2.25 & 0.94 & 2.33 & 1.43 & $2.13^{*}$ & 1.16 & 2.15 & 1.08 & 2.45 & 1.07 & 1.97 \\
\hline $\mathrm{ZTT}(\mathrm{G})$ & 6.17 & 1.62 & 6.81 & 1.50 & 7.62 & $1.43^{*}$ & 6.82 & 1.45 & 6.82 & 1.51 & 7.50 & 1.64 \\
\hline T-Bil (G) & 0.64 & 1.52 & 0.56 & 1.46 & 0.60 & 1.49 & 0.60 & 1.45 & 0.57 & 1.52 & 0.58 & 1.45 \\
\hline D-Bil & 0.31 & 0.16 & 0.26 & 0.14 & 0.26 & $0.13 *$ & 0.27 & 0.13 & 0.27 & 0.15 & 0.25 & 0.12 \\
\hline I-Bil & 0.39 & 0.18 & 0.34 & 0.14 & 0.39 & 0.18 & 0.38 & 0.17 & 0.36 & 0.16 & 0.37 & 0.16 \\
\hline Ch-E & 5025.3 & 827.5 & 5088.2 & 777.2 & 4900.6 & 865.5 & 4979.1 & 901.5 & 5021.4 & 814.3 & 5264.9 & 753.9 \\
\hline $\mathrm{TP}$ & 7.32 & 0.44 & 7.36 & 0.34 & 7.22 & 0.30 & 7.26 & 0.34 & 7.34 & 0.35 & 7.43 & 0.36 \\
\hline Alb & 4.58 & 0.30 & 4.61 & 0.25 & 4.45 & $0.22 *$ & 4.53 & 0.24 & 4.62 & 0.27 & 4.50 & 0.22 \\
\hline$A / G$ & 1.68 & 0.20 & 1.70 & 0.21 & 1.62 & 0.22 & 1.68 & 0.22 & 1.71 & 0.19 & 1.57 & 0.24 \\
\hline T-Chol & 196.1 & 38.0 & 185.5 & 33.0 & 197.5 & 35.1 & 192.2 & 34.1 & 184.2 & 31.4 & 196.0 & 22.7 \\
\hline TG $(G)$ & 139.4 & 1.9 & 125.9 & 1.8 & 157.7 & 1.6 & 146.9 & 1.8 & 120.5 & 1.8 & 117.8 & 1.5 \\
\hline FFA $(G)$ & 0.27 & 1.81 & 0.33 & 1.91 & 0.30 & 1.76 & 0.30 & 1.91 & 0.35 & 1.77 & 0.33 & 1.83 \\
\hline HDL & 50.8 & 11.6 & 49.8 & 13.9 & 48.2 & 11.5 & 47.3 & 11.8 & 51.3 & 13.2 & 50.7 & 14.7 \\
\hline LDL & 466.3 & 105.1 & 436.8 & 109.7 & 481.8 & 83.2 & 471.3 & 109.6 & 426.8 & 101.5 & 470.4 & 88.0 \\
\hline VLDL (G) & 108.0 & 1.7 & 99.2 & 1.7 & 117.2 & 1.5 & 112.8 & 1.6 & 90.5 & 1.7 & 99.1 & 1.5 \\
\hline Chilomicron $(\mathrm{G})$ & 59.6 & 2.2 & 58.6 & 2.2 & 75.9 & 1.9 & 68.0 & 2.2 & 59.7 & 2.2 & 47.7 & 1.9 \\
\hline Fructosamine (G) & 247.0 & 1.1 & 246.8 & 1.1 & 241.9 & 1.1 & 244.3 & 1.1 & 246.5 & 1.1 & 243.4 & 1.1 \\
\hline $\operatorname{HBA}_{l_{c}}(\mathrm{G})$ & 4.91 & 1.08 & 4.85 & 1.07 & 5.07 & $1.08 *$ & 4.91 & 1.09 & 4.91 & 1.07 & 5.00 & 1.09 \\
\hline $\mathrm{Cr}$ & 0.94 & 0.13 & 0.92 & 0.10 & 0.93 & 0.13 & 0.92 & 0.12 & 0.91 & 0.11 & 0.95 & 0.11 \\
\hline UA & 5.49 & 1.34 & 5.68 & 1.14 & 5.33 & 0.97 & 5.57 & 1.17 & 5.54 & 1.01 & 5.63 & 1.32 \\
\hline BUN & 13.3 & 3.3 & 13.9 & 3.3 & 14.1 & 3.7 & 13.6 & 3.3 & 13.5 & 3.5 & 15.3 & 4.2 \\
\hline $\mathrm{Na}$ & 140.5 & 2.0 & 140.9 & 2.1 & 140.8 & 2.0 & 140.7 & 2.0 & 140.8 & 2.0 & 140.5 & 2.8 \\
\hline$K(G)$ & 4.32 & 1.15 & 4.49 & 1.12 & 4.50 & $1.14^{* * *}$ & 4.51 & 1.12 & 4.54 & 1.13 & 4.40 & 1.16 \\
\hline $\mathrm{Cl}$ & 101.0 & 2.2 & 101.2 & 2.6 & 101.7 & 2.4 & 101.3 & 2.5 & 101.1 & 2.8 & 101.8 & 3.0 \\
\hline $\mathrm{Ca}$ & 9.16 & 0.37 & 9.23 & 0.37 & 9.08 & 0.33 & 9.13 & 0.33 & 9.23 & 0.39 & 9.23 & 0.31 \\
\hline \multicolumn{13}{|l|}{ Urine } \\
\hline $\operatorname{NAG}(G)$ & 3.32 & 2.50 & 3.44 & 2.17 & 3.93 & 2.37 & 3.61 & 1.94 & 3.51 & 2.21 & 4.22 & 3.81 \\
\hline$\beta_{2}-\mathrm{MG}(\mathrm{G})$ & 153.8 & 1.8 & 152.7 & 1.7 & 168.2 & 1.8 & 150.8 & 1.7 & 157.9 & 1.7 & 165.3 & 2.0 \\
\hline
\end{tabular}

Abbreviations and units of the items are shown in the Note of Table 4. (G) indicates that the value were statistically analyzed after converting into the geometric values. a: Referent workers. b: Hydrazine hydrate workers who are estimated to have been exposed less than 5 ppm-year. : Hydrazine hydrate workers who are estimated to have been exposed 5 ppm-year or above. *,**: p<0.05, 0.01 by ANOVA.

"nightmares" might to be related to sleep quantity or quality or psychological, neurological, or neurobehavioral effects $^{23,24)}$. But the significant increase in the complaint of "nightmares" without other sleep-related, psychological, neurological, or neurobehavioral complaints might be insufficient to support the assertion that this complaint of "nightmares" was caused by $\mathrm{HH}$ exposure.

The biological half lives of urinary hydrazine + acetylhydrazine in $\mathrm{HH}$-exposed workers were 1.68 for the rapid acetylation type, 3.01 for the intermediate acetylation 
type, and $4.46 \mathrm{hr}$ for the slow acetylation type ${ }^{25)}$. Though $\mathrm{HH}$-exposed workers of the slow acetylation type were expected to be more affected than those of the rapid or intermediate acetylation type because of the differences among the half lives of three phenotypes of NAT2, we failed to detect any significant differences in health among these 3 NAT2 phenotypes. The level of $\mathrm{HH}$ exposure in this study may be too low to detect differences in the effects of $\mathrm{HH}$ exposure among the 3 NAT2 phenotypes.

\section{Conclusion}

The results of this cross-sectional study suggested that there was no relation between a current, mean hydrazine concentration of $0.0109 \mathrm{ppm}$, and cumulative $\mathrm{HH}$ exposure and its health effects by means of differences of NAT2 phenotypes. Further follow-up of this study population or new epidemiological studies consisting of workers with higher $\mathrm{HH}$ exposure levels will be necessary to upgrade the information on the health effects of $\mathrm{HH}$ exposure in both quality and quantity.

Acknowledgments: The authors thank the members of the Hydrazine Section of the Japan Inorganic Chemical Industry Association and the staffs of the divisions of occupational health and environmental administration in the five factories for their cooperation. This study was supported by a grant from the Japan Inorganic Chemical Industry Association.

\section{References}

1) Ekshtat BY. Maximum permissible concentrations of $\mathrm{HH}$ and phenylhydrazine in water bodies. Hyg Sanit 1965; 30: 191-197.

2) Bozo Research Center Inc. An acute dermal toxicity study of $100 \% \mathrm{HH}\left(\mathrm{N}_{2} \mathrm{H}_{4} \cdot \mathrm{H}_{2} \mathrm{O}\right)$ in rabbits. Bozo Research Center Inc. B-2485 1993.

3) Huntingdon Research Centre. Hydrazine $64 \%$ aqueous solution. Acute inhalation toxicity in rats 1 -hour exposure. HRC Report 1993.

4) Reid FJ. Hydrazine and lupus. Br Med J 1965; 2: 1246.

5) Evans DM. Two cases of $\mathrm{HH}$ dermatitis without systemic intoxication. Br J Ind Med 1959; 16: 126-127.

6) Sotaneimi E, Hirvonen J, Isomaki H, Takkunen J, Kaila J. Hydrazine toxicity in the human report of fetal case. Ann Clin Res 1971; 3: 30-33.

7) Richter ED, Gal A, Bitchatchi E, et al. Residual neurobehavioral impairment in a water technician exposed to hydrazine-containing mixture. Israel J Med Sci 1992; 28: 598-602.

8) Wald N, Boreham J, Doll R, Bonsall J. Occupational exposure to hydrazine and subsequent risk of cancer. Br J Ind Med 1984; 41: 31-34.

9) Morris J, Densem JW, Wald NJ, Doll R. Occupational exposure to hydrazine and subsequent risk of cancer. Occup Environ Med 1995; 52: 43-45.

10) Haun CC, Kinkead ER. Chronic inhalation toxicity of hydrazine. In: Proceeding of the 4th Annual Conference on Environmental Toxicology, Aerospace Medical
Research Laboratory, Wright Patterson Air Force Base, OH. 1973: 351-363.

11) MacEwen JD, McConnell EE, Beck KC. The effects of 6-month chronic low level inhalation exposures to hydrazine on animals. In: Proceeding of the 5th Annual Conference on Environmental Toxicology, Aerospace Medical Research Laboratory, Wright Patterson Air Force Base, OH. 1974: 225-235.

12) Vemot EH, MacEwen JD, Bruner RH, et al. Long term inhalation toxicity of hydrazine. Fund Appl Toxicol 1985; 5: 1050-1064.

13) International Agency for Research on Cancer. IARC Monographs on the Evaluation of Carcinogenic Risk of Chemicals to Man, Vol. 4, Some Aromatic Amines, Hydrazine and Related Substances, N-Nitroso Compounds and Miscellaneous Alkylating Agents. Lyon: IARC, 1974: 127-136.

14) ACGIH. 1996-1997. Threshold limit values for chemical substances and physical agents and Biological Exposure Indices. Cincinnati: ACGIH, 1996.

15) NIOSH. Manual of Analytical Methods, 3 rd edition, $P$ \& CAM 248 Hydrazine Compounds. In: Air. U.S. Department of Health, Education, and Welfare 1977; 1: 248-1-248-6.

16) Timbrell JA, Harland SJ. Identification and quantification of hydrazine in the urine of patients treated with hydralazine. Clin Pharmacol Ther 1979; 26: 81-88.

17) Lin HJ, Han C, Lin BK, Hardy S. Slow acetylator mutations in the human polymorphic $\mathrm{N}$-acetyltransferase gene in 786 Asians, Blacks, Hispanics, and Whites: Application to metabolic epidemiology. Am J Hum Genet 1993; 52: 827-834.

18) Inoue T. A table for subjective symptom questionnaires for solvent workers. In: Japan Industrial Health and Safety Association, ed. Health management of solvent workers. Tokyo: Japan Industrial Health and Safety Association, 1993; 66-67 (in Japanese).

19) Japan Society of Occupational Health. Recommendation of occupational exposure limits (1994). Jpn J Ind Health 1994; 36: 273-276.

20) Tanaka $T$, Nagai $M$, Yoshihara $S$, et al. Changing pattern of age-specific prevalence of hepatitis $B$ surface antigen and corresponding antibody in Japan. Am J Epidemiol 1986; 124: 368-371.

21) Nishioka $K$. Hepatitis $C$ virus infection in Japan. Gastroenterol Jpn 1991; 26 suppl 3: 152-155.

22) Akbar SM, Onji M, Kanaoka M, et al. The seroepidemiology of hepatitis A and B in a Japanese town. Asia-Pacific J Public Health 1992-93; 6: 26-29.

23) Lindelof $B$, Almkvist $O$, Gothe $C J$. Sleep disturbances and exposure to organic solvents. Arch Environ Health 1992; 47: 104-106.

24) Kishi R, Itoh I, Shizu S, Harabuchi I, Miyake H. Symptoms among workers with long-term exposure to methyl bromide. An epidemiological study. Jpn J Ind Health 1991; 33: 241-250.

25) Koizumi A, Nomiyama $T$, Tsukada $M$, et al. Evidence of $\mathrm{N}$-acetyltransferase allele associated metabolisms of hydrazine in Japanese workers. J Occup Environ Med 1998; 40: 217-222. 